\title{
Perceptual Enhancement for Arabic Reading: An Intervention to Support Fluency and Automaticity in Grade One
}

Corresponding Author:

Elisabeth Wilson

Submitted: May 10, 2020

Accepted: July 10, 2020

Published: July 29, 2020

Production and Hosting by Knowledge E

(c) Elisabeth Wilson et al. This article is distributed under the

terms of the Creative

Commons Attribution

License, which permits unrestricted use and redistribution provided that the original author and source are credited.

Managing Editor:

Natasha Mansur

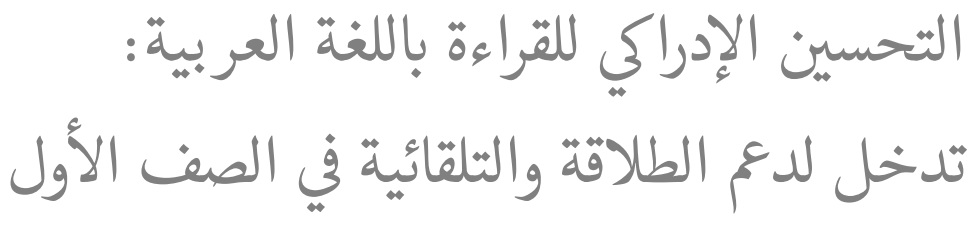

Elisabeth Wilson¹, Soohyun Jeon¹, Holly Cook', and Helen Abadzi²

${ }^{1}$ Sheikh Saud bin Saqr Al Qasimi Foundation for Policy Research

${ }^{2}$ University of Texas at Arlington

\section{Abstract}

This study, conducted in the United Arab Emirates, piloted a curriculum to increase early grade reading fluency. A curriculum with enhanced perceptual features, such as font size and spacing was used with grade one students in four schools to detect any significant difference in students' reading speed and reading accuracy after one year. Three hundred forty-five grade one students participated in the pilot-174 in the intervention group and 171 in the control group ( $d s=0.330 .47$ ). At the end of the year, students in the intervention group read more letters and words correctly on average in one minute $(p<.01)$ and in an entire text $(p<.01$ for letters; $\mathrm{p}<.001$ for words) than those in the control group. These results suggest that curriculum with perceptual enhancement may be useful in facilitating early Arabic reading fluency.

المالخصن

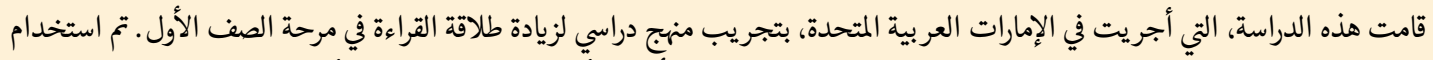

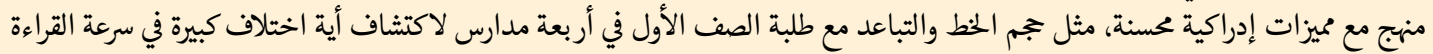

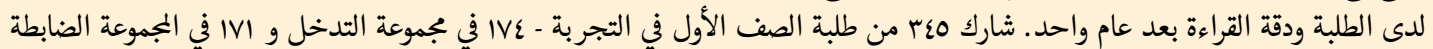

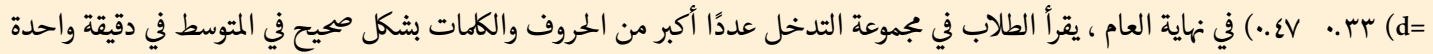

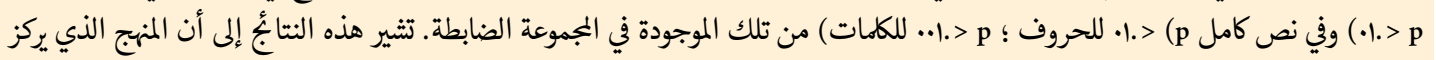

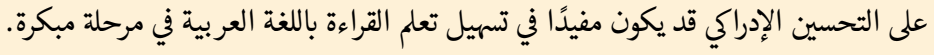

Keywords: Arabic reading; early grade reading; reading accuracy; reading fluency; perceptual enhancement; Arabic reading curriculum

الكالمات المفتاحية: القراءة العربية، قراءة الصف الأول، دقة القراءة ،قراءة الطلاقة، تعزيز إدراك منهج القراءة العربية 


\section{Introduction}

International, large-scale student assessments such as Program for International Student Assessment (PISA) and Trends in International Mathematics and Science Study (TIMSS) have taken a prominent role in informing education policy by allowing policymakers and researchers to compare education outcomes between countries. In the Arab world these assessments have raised concerns as students' scores are below the global average, particularly in reading proficiency (OECD, 2019; Jackson \& Kiersz, 2016). These low performances could indicate future economic and workforce challenges for the region. Some countries have set ambitious goals to increase the quality of education. The United Arab Emirates (UAE) has included international assessment rankings in its national agenda. UAE aims for students to score among the top 20 on PISA and top 15 on TIMSS (UAE, 2017). However, students continue to perform lower than the OECD average. In reading, they ranked 46th, in mathematics 50th, and in science 49th. On the reading assessment, approximately 43 percent of the students were below Level 2 proficiency, unable to identify the main idea in a text of moderate length (OECD, 2019) ${ }^{1}$.

In order to strengthen Arabic students' reading fluency as a step toward improving reading comprehension and overall quality of education, an early grade reading curriculum called lqra was developed by the Al Qasimi Foundation together with cognitive psychologist, Dr. Helen Abadzi. A similar reading curriculum had been piloted in The Gambia and India (Karim et al., 2016; lyengar, 2019; lyengar, 2018). The textbook developed was based on how the brain uses decoding and memory function in learning to read (Abadzi \& Martelli, 2014; Abdelhadi et al., 2011; Pelli et al., 2007). Different from other existing Arabic reading curriculum, Iqra approximates critical size and spacing parameters necessary for students to practice and attain automaticity more quickly.

The Iqra curriculum was piloted in four primary schools in the UAE with 345 students over one school year. The intervention group consisted of 174 students; 171 students were included in the control group. The study's research questions asked whether students who used the Iqra curriculum in addition to the mainstream Arabic curriculum would demonstrate greater reading fluency after one year than students who only used the mainstream Arabic reading curriculum. Assessments of students' reading speed and accuracy were conducted at the beginning, middle, and end of the year. The following sections provide the theoretical background and methodological approach of the study, then describe the design, and results. The article concludes with a discussion of implications, limitations, and thoughts on future research.

\section{Literature Review}

A number of features of Arabic set it apart as a difficult language to read fluently. This section focuses on some of the challenges highlighted in the literature and how they have influenced the development of the lqra curriculum. Research has focused on how reading fluency develops and how speed and accuracy lead to increased reading comprehension (Fuchs et al., 2001). 
Many factors have been shown to affect reading comprehension. Reading comprehension results through a combination of decoding and listening comprehension (Gough \& Tunmer, 1986). Decoding, or recognizing printed symbols and matching them with sound is a process that normally develops automatically. Although readers may initially recognize and read letters individually, with practice, their brains begin to connect the sequences of symbols, such as individual letters and sounds into larger patterns or units, such as words (Goulandris, 2003). When this process happens more quickly, it can promote better comprehension (Carnine et al., 1990; Dehaene et al., 2015; Miller, 1956; Peterson \& Peterson, 1959; Perfetti, 2007; Yigal \& Sekuler, 2008). Practicing patterns can help students to develop skills to read faster (Pariyadath et al., 2012; Speelman \& Kirsner, 2005). In addition to decoding, research points to factors such as morphological awareness, text context, and word recognition skills that may affect accuracy and reading comprehension (Abu-Leil et al., 2014; Fuchs et al., 2001; Perfetti, 1992). Also, phonological structuring that exists prior to reading may also play a role in reading acquisition (Elbro \& Pallesen, 2002; Wydell \& Butterworth, 1999; Ziegler \& Goswami, 2005).

Visual parameters, or perceptual features that can maximize readers' decoding and reading speed include size and spacing of letters and words on a page (Pelli et al., 2007). When letters are sufficiently spaced, their features are more easily differentiated from other letters (Chung, 2002; Zhu et al., 2016; Levi, 2008). The effects of increased perceptual learning are best understood as a change in the ability of readers to complete higher-level integration or association and read out sensory information to make particular decisions (Green et al., 2015). This process, potentially more important for students learning to read, can be enhanced through training or visual experiences (Chen \& Vellutino, 1997; Duke et al., 2004; Gibson, 1963; Gori \& Facoetti, 2014; Watanabe \& Sakaki, 2015).

Procedural memory is another aspect that enables the reader to become more fluent and the reading process to become automatic (LaBerge \& Samuels, 1974). Procedural memory is used to detect and process script so that the brain can transition it to working memory for interpretation. If the process moves too slowly, the contents in the working memory can be erased (Miller, 1956; Peterson \& Peterson, 1959). However, when the process is fast and accurate, readers have more time to connect ideas within the text and think critically about them (Klauda \& Guthrie, 2008; LaBerge \& Samuels, 1974).

\subsection{Complexities of the Arabic Script}

In beginning to read Arabic, aspects of decoding and working memory may slow readers down. Firstly, the script is visually complex. In total, there are 29 letters and eight diacritics (harakat) that indicate short vowels. The text is cursive, and some letters can have up to four different shapes depending on their position within a word. Each letter is drawn in an isolated form when it is written alone and can have up to three more forms when it is connected to other letters. Additionally, the shape of the Arabic letters can change dramatically depending on the font (Rashid, 2011). 
Even though short vowels are often predictable in Arabic and other Semitic languages, omitting them causes many words to become homographic which can slow down the reading speed (Abu-Rabia, 2001; Abu-Rabia, 1999; Taha, 2013). Adding harakat back to text can increase reading speed (Maroun \& Hanley, 2017). To predict successfully, readers must know Modern Standard Arabic (MSA) well. Interestingly, most Arab countries print the TIMSS and PIRLS tests without short vowels, even though fourth graders may still be learning how to process unvoweled text (Asadi et al., 2017).

Recent Arabic language research with early grade readers show the complex interaction of language, knowledge, and visual issues of the Arabic script. Arabic reading first graders had a reading error rate of 23 percent in contrast to European first graders who had a zero percent error rate by the end of grade one (Natour et al., 2016; Seymour et al., 2003). This difference in error rates indicates the innate perceptual difficulties of Arabic and the challenge for students' working memory to interpret the meaning of Arabic text quickly and accurately (Abadzi, 2017).

\subsection{Arabic Diglossia and Reading Fluency}

Arab students, learning to read Arabic, also face the challenge of diglossia which is deeply embedded in Arabic culture. MSA, a linguistic descendent of Classical Arabic, the form used in the Holy Quran, is the form of Arabic used in formal education (Mahfoudhi et al., 2011; Knipp, 2014; Saiegh-Haddad \& Joshi, 2014). However, MSA is different than ammia, the colloquial version of Arabic spoken at home. Each Arab country has two vernaculars-one that they use as the dominant mode of communication and the other, MSA, as a lingua franca. Differences between MSA and ammia exist in verb and noun endings, expressions, vocabulary, and pronunciation. Research suggests that students across the Middle East view MSA as a foreign language (Ayari, 1996; Ibrahim \& Aharon-Peretz, 2005; Saiegh-Haddad, 2007; Eviatar \& Ibrahim, 2014). Young students who use only ammia may find it hard to make sense of MSA without training. As they begin school, they must acquire the MSA grammar and vocabulary in order to process the information being taught (Eviatar \& Ibrahim, 2014). When initially learning to identify Arabic letters, readers more slowly identify letters that have a different sound in their dialect (Saiegh-Haddad, 2003; Saiegh-Haddad \& Joshi, 2014). While children are very good at pattern recognition, they need multiple opportunities to sample various visual patterns and grammatical forms; since MSA is not used in daily life, students cannot sufficiently sample content to make sense of its visual complexities and large grammatical framework without explicit instruction (Abadzi, 2017; Taha \& SaieghHaddad, 2016; Schiff \& Saiegh-Haddad, 2018).

\subsection{Development of the Iqra curriculum}

Considering the development of reading fluency along with the complexities of Arabic script and diglossia, the lqra textbook was first developed and piloted for the following reason. Using the textbook, the study aimed to find whether training in decoding and repeated exposure to patterns in MSA would increase early grade readers' reading 
speed and accuracy to place them on a better trajectory to demonstrate increased reading fluency and comprehension and improved scores on global education assessments.

Currently, the mainstream reading textbooks in the UAE are designed to be childcentered and have a communicative approach. Textbook pages are colorful and crowded with pictures of national foods, familiar objects, and popular landmarks to catch and keep children's attention. Letters are introduced in traditional alphabetical order, yet latter letters are also introduced in the process. Language skills are mixed throughout the reading curriculum. As students learn to read, they are also taught to write and dialogues implicitly present various MSA grammatical structures.

The Iqra textbook follows curriculum piloted with grade one students in The Gambia and India by the Earth Institute of Columbia University (Karim et al., 2016; Iyengar, 2019; lyengar, 2018). The Iqra curriculum takes a simpler approach than mainstream curriculum. Reading is taught separate from other language skills. There are minimal pictures to distract the students as they read, and letters are introduced one-by-one. Each has one picture with it to help readers guess the letter. The letters themselves are printed in large font with loose spacing and ordered by visual complexity. Easier letters, ones that have fewer standard written forms, come first. The first four letters in the Iqra textbook have only one written form. More complex letters that have a different shape if they are the first, middle, or last letter of a word, are introduced later. Harakat are included throughout with the letters. Figure 1 shows a sample page from the Iqra textbook.

\section{Figure 1}

Sample from lqra Reading Textbook Page

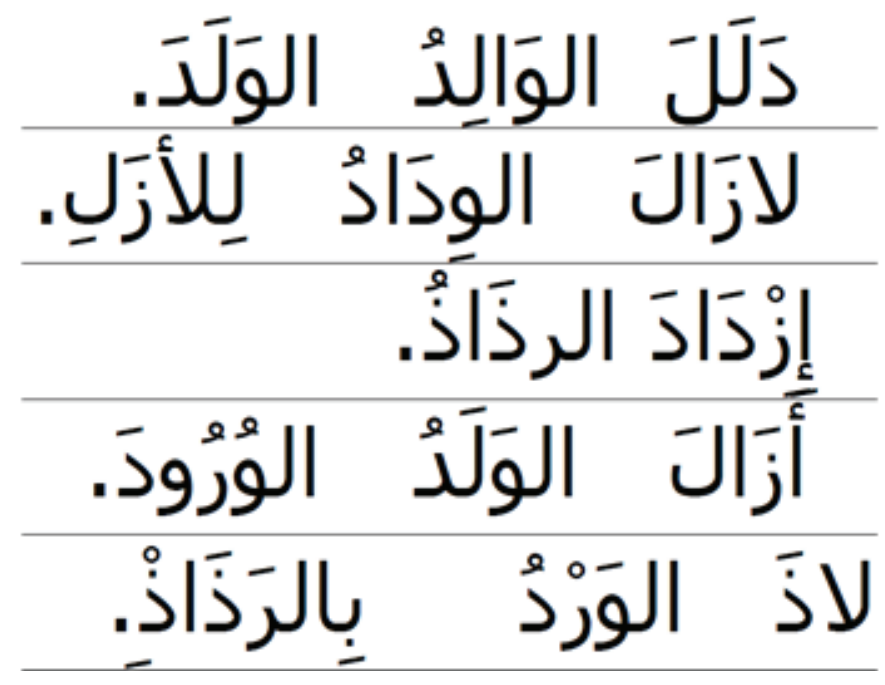

Patterns of letter combinations are shown in a recurrent order at the beginning of each lesson for children to develop inference skills, sense analogy, and read whole words more quickly. The lqra textbook gradually introduces words based on letters that have been taught. As more letters are taught, more words, and then full simple sentences are included for the students to read. When reading from their textbooks, students 
are taught to focus their eyes by using their finger to follow the lines of letters and combinations of letters and read them aloud repeatedly as a group and then individually from each page.

\subsection{Study Purpose}

The main purpose of the present study is to examine the effects of the lqra curriculum on grade one students' speed and accuracy in letter identification and word reading. Therefore, we pose the following research questions.

Research Question 1: Do students who participated in the Iqra curriculum identify letters and read words faster than students who only attended classes using the mainstream Arabic language curriculum at the end of first year?

Research Question 2: Do students who participated in the lqra curriculum identify letters and read words more accurately than students who only attended classes using the standard Arabic language curriculum at the end of first year?

\section{Methodology}

\subsection{Participants}

In total, 400 students participated in the Iqra pilot at four government primary schools in Ras Al Khaimah, United Arab Emirates. ${ }^{2}$ This was a convenience sample, based on relationships that the Al Qasimi Foundation had with these four schools whose teachers had participated in previous professional development programming. As such, these schools had demonstrated an openness to trying new pedagogies in the past. At each school, four classes of approximately 25 students participated. Two classes of students used the Iqra curriculum (intervention) and two did not (control), resulting in eight intervention and eight control classrooms all together. The assignment of intervention and control group was determined by the schools, based on instructors' availability.

Once the data was analyzed, students who had not taken all three assessments $(n=43)$ and students who were identified as having learning difficulties by their schools $(n=12)^{3}$ were excluded from the sample. These deletions resulted in a sample size of 345 students. This included 76 students from School 1, 99 students from School 2, 75 students from School 3, and 95 students from School 4. The final sample consisted of 174 and 171 students in the intervention and control groups, respectively (55\% girls and $45 \%$ boys in each group). Table 1 shows the participants from each school by gender and group. Besides gender, no other demographic information such as socioeconomic status was collected. ${ }^{4}$

\subsection{Procedure}

When the lqra reading textbook was complete, four other government schools, also with previous relationships with the Foundation were approached with the initial positive 


\section{Table 1}

Number of Participants by Group and Gender

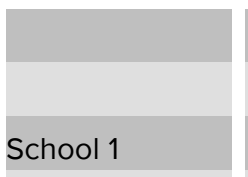

School 2

School 3

School 4

\begin{tabular}{|c|}
\hline Intervention \\
\hline Female $(\mathrm{n}=95)$ \\
\hline 20 \\
27 \\
24 \\
24 \\
\hline
\end{tabular}

\begin{tabular}{|c|c|}
\hline \multicolumn{2}{|c|}{ Control $(n=171)$} \\
\hline Female $(n=94)$ & Male $(n=77)$ \\
\hline 21 & 14 \\
\hline 23 & 28 \\
\hline 24 & 13 \\
\hline 26 & 22 \\
\hline
\end{tabular}

Male $(n=79)$
21
21
14
23

Total $(n=345)$ 76 99 75 95

findings from the first lqra pilot and invited to participate in a full-year pilot. Each school agreed to participate and support the study by providing one or two staff members with training and then implement the curriculum through the year with support from the Foundation staff who would be conducting bi-monthly class visits.

Prior to the start of the academic year, school principals and instructors attended a brief orientation on how to use the Iqra curriculum. The orientation included the rationale behind the curriculum as well as its efficiency, placing emphasis on the minimal preparation required on the part of the instructor to implement lqra lessons. In terms of resources, all that was needed were hard copies of the lqra textbook for each student and a computer with projector to digitally display the textbook pages on the class whiteboard.

Students' reading fluency was assessed at the beginning, middle, and end of the year to detect any differences between the students who received the Iqra curriculum plus the standard Arab reading curriculum and those who received only the standard Arab reading curriculum. Assessments measured the number of letters and words students could read in one minute and the number of letters and words they could correctly identify. We expected students' reading fluency to be very low at the beginning of the year because they had not received formal Arabic language instruction before grade one. However, by the middle of the year, we anticipated that students in the intervention group would improve more rapidly than the control group over the course of the year.

Assessments were conducted by Foundation staff members, who were oriented on the tools prior to each assessment. An additional staff member monitored the room and tracked the tests collected during the assessment. Instructors from the school were also on hand to keep the testing environment calm for the students.

Each week, the intervention group of students had five 45-minute Arabic lessons using the standard Arabic language curriculum and two additional 45-minute lessons using the lqra curriculum. Those lessons were taught during a class period that was normally reserved for extracurricular activities. The control group of students had five 45-minute Arabic lessons using the Ministry of Education curriculum each week and did not have any of the lqra lessons.

Each lesson followed the same format. First was a group warm-up and review of previously taught letters. Next, a new letter was introduced, and students read exercises projected onto the front classroom wall. Afterward, students read the same exercises independently in their own printed copy of the lqra textbook while the instructor passed 
by each student and gave brief feedback and encouragement to stay on-task. The instructor would direct students to point to each letter or word on the page as they read to keep their eyes focused on the text.

\subsection{Measures}

The tool used to assess students' reading speed and accuracy at the beginning, middle, and end of the year was a modified version of an Early Grade Reading Assessment (EGRA) previously used in Jordan to measure the fluency of native Arabic-speaking children (RTI International, 2016). It consisted of two exercises: identifying letters and reading words. Exercises did not measure reading comprehension because it was uncertain whether students would understand enough MSA to respond to comprehension questions reliably.

To measure letter identification speed, students were asked to identify Arabic letters individually with harakat and simple letter combinations in a span of one minute. The exercise was simultaneously used to measure letter identification accuracy. Students were stopped after making five errors, even if one minute had not passed. If they had not made five errors within the first minute, they were encouraged to keep identifying letters until they made five mistakes, or until they finished identifying the letters on the page. If a student initially made a mistake identifying a letter but then amended their answer, it was counted correct.

Next, to measure students' reading speed, students were given one minute to read a 49-word paragraph. The exercise was simultaneously used to measure reading accuracy. Students were stopped after making five errors. If they had not made five errors within the first minute, they were encouraged to keep reading until they made five errors, or until they finished reading the paragraph. If a student initially made a mistake but then amended their answer, it was counted correct.

\subsection{Data Analysis}

SPSS Statistics 25 was used to perform a series of independent samples t-tests to examine any statistically significant differences between the intervention and control groups in their reading speed and accuracy. ${ }^{5}$ First, the pre-test mean scores on the letter identification and word reading tasks were compared to assess baseline equivalence for the intervention and control groups. Next, the average number of letters and words read correctly (per minute scores for speed and total number scores for accuracy) were compared as well as gain scores (changes between post-test and pretest) at mid-test and post-test between the intervention and control groups to examine the effects of lqra curriculum on students' speed and accuracy in letter identification and word reading. ${ }^{6}$ 


\section{Results}

\subsection{Research Question 1: Speed differences in letter identification and word reading}

To examine any differences in the speed of the letter identification and word reading between the intervention and control groups, the average number of letters identified and words read correctly per minute were compared using a series of t-tests. As shown in Table 2, on the pre-test, there were no statistically significant differences between the intervention and control groups on both letter identification and word reading mean scores. At mid-year assessment, however, the intervention group's mean scores were significantly higher than the control group's scores on both per minute letter identification $(t(267)=2.88, p=.004,95 \% \mathrm{Cl}[1.65,8.82], d=0.35)$, and word reading assessments, $(t(343)=3.50, p=.001,95 \% \mathrm{Cl}[1.46,5.21], d=0.38)$, indicating that students in the lqra group identified letters and read words faster than those in the control group.

\section{Table 2}

Mean Differences between the Intervention and Control Groups in the Number of Letters Identified and Words Read Correctly per Minute

\begin{tabular}{|c|c|c|c|c|c|c|c|c|c|c|}
\hline \multirow[t]{3}{*}{ Time } & \multicolumn{5}{|c|}{ Letters } & \multicolumn{5}{|c|}{ Words } \\
\hline & \multicolumn{2}{|c|}{ Intervention $(n=133$ ) } & \multicolumn{2}{|c|}{ Control $(n=136)$} & \multirow[t]{2}{*}{$t(267)$} & \multicolumn{2}{|c|}{ Intervention $(n=174)$} & \multicolumn{2}{|c|}{ Control $(n=171)$} & \multirow[t]{2}{*}{$t(343)$} \\
\hline & M & SD & M & SD & & $M$ & SD & M & SD & \\
\hline Pre-test & 16.68 & 26.69 & 17.69 & 29.81 & -0.29 & 1.07 & 5.17 & 1.11 & 3.15 & -0.09 \\
\hline Mid-test & 23.09 & 14.94 & 17.85 & 14.92 & $2.88^{* *}$ & 9.53 & 9.36 & 6.19 & 8.29 & $3.50^{* * *}$ \\
\hline Post-test & 36.57 & 20.53 & 29.49 & 22.45 & $2.70^{* *}$ & 16.05 & 11.37 & 12.23 & 12.01 & $3.03^{* *}$ \\
\hline $\begin{array}{l}\text { Difference } \\
\text { (post-test - } \\
\text { pre-test) }\end{array}$ & 19.89 & 30.11 & 11.80 & 31.12 & $2.17^{*}$ & 14.98 & 11.05 & 11.12 & 11.05 & $3.24^{* *}$ \\
\hline
\end{tabular}

To examine if students in the intervention group outperform students in the control group in terms of speed of letter identification and word reading after participating in a full-year lqra intervention, the post-test means between two groups were compared. As presented in Table 2, the intervention group scored significantly higher than the control group on both the average total number of letters and words correctly read in one minute $(t(267)=2.70, p=.007,95 \% \mathrm{Cl}[1.91,12.25], d=0.33$ for letters; $t(343)$ $=3.03, p=.003,95 \% \mathrm{Cl}[1.34,6.29], d=0.33$ for words). Students in the intervention group correctly identified seven more letters and read approximately four more words per minute on average than those in the control group. When comparing the gains between pre- and post-test between two groups, students in the intervention group had greater gains on average than students in the control group, indicating that the intervention group identified approximately 20 more letters and read 15 more words correctly on average while the control group gained approximately 12 letters and 11 
words over pre-test assessments $(t(267)=2.17, p=.031,95 \% \mathrm{Cl}[0.74,15.45], d=0.26$ for letters; $t(343)=3.24, p=.001,95 \% \mathrm{Cl}[1.51,6.19], d=0.35)$.

Figure 2 and Figure 3 display the pre-test, mid-test, and post-test scores between the intervention and control groups in average total number of letters identified and words read correctly per minute, showing the higher performance of the intervention group in the speed of identifying letters and reading words.

\section{Figure 2}

Pre-test, Mid-test, and Post-test Means of the Intervention and Control Groups on the Per Minute Letter Identification Assessment

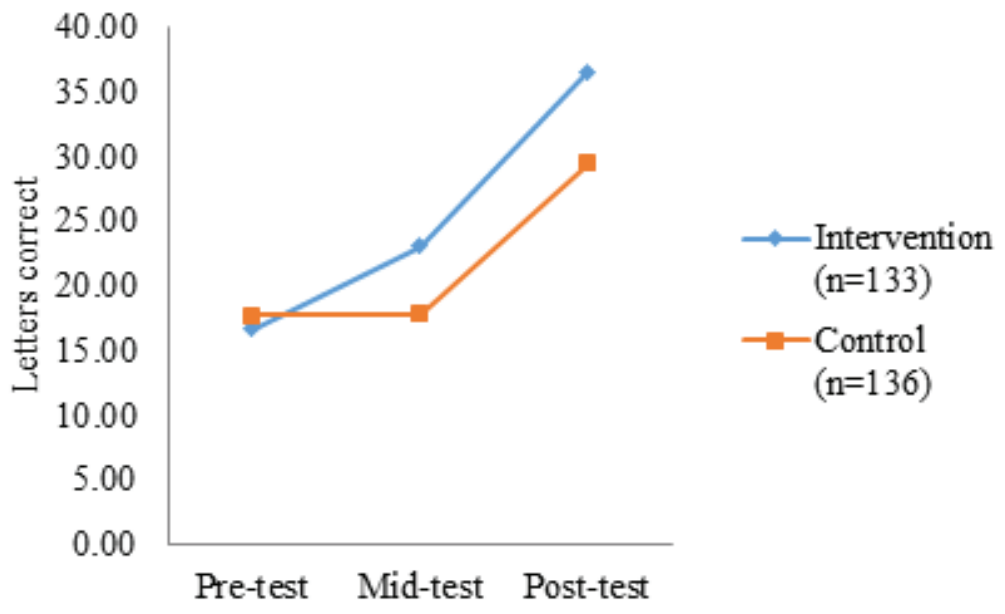

\section{Figure 3}

Pre-test, Mid-test, and Post-test Means of the Intervention and Control Groups on the Per Minute Word Reading Assessment

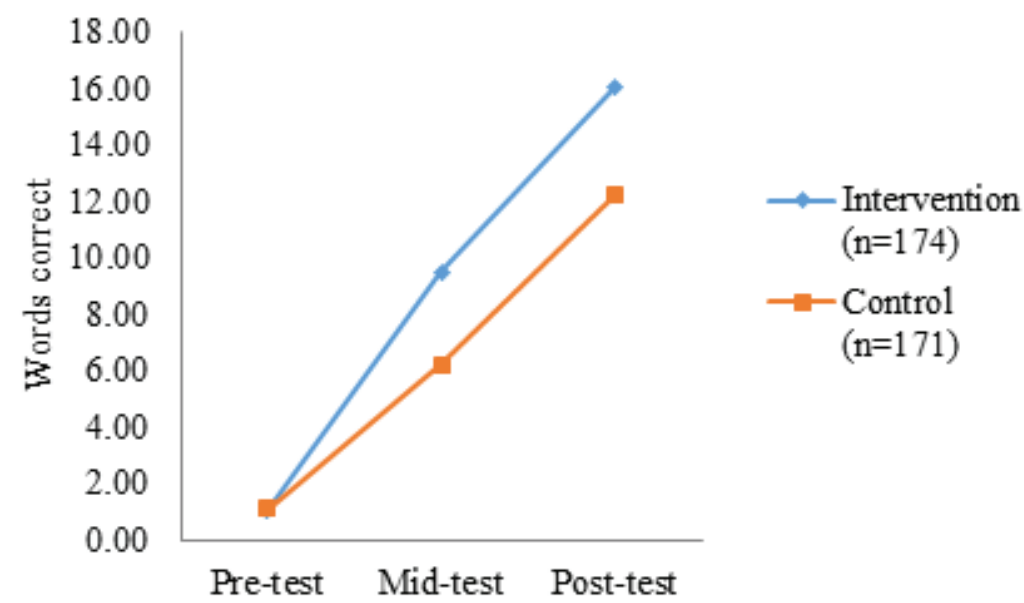

When the post-test results are examined in terms of the percent correct scores ${ }^{7}$ for letter identification, no notable difference was found between the two groups $(97 \%$ for the intervention and $94 \%$ for the control groups), indicating both groups reached a high level of accuracy in the per-minute letter identification. As presented in Table 3, 
however, the intervention group identified significantly more letters $(t(267)=2.57, p=$ $.011,95 \% \mathrm{Cl}[1.48,11.26], d=0.32)$ and made fewer errors $(t(267)=-3.14, p=.002,95 \% \mathrm{Cl}$ $[-1.15,-0.26], d=-0.38)$ per minute than the control group. The average percent correct scores for word reading was also higher for the intervention group than for the control group, indicating the students receiving the lqra curriculum could read words correctly in one minute with 91 percent accuracy on average, while those in the control group read words correctly with 86 percent accuracy.

\section{Table 3}

Post-test Mean Numbers of Letters and Words Attempted and Errors Made per Minute for the Intervention and Control Groups

\begin{tabular}{|c|c|c|c|c|c|c|c|c|c|c|}
\hline \multirow[t]{3}{*}{ Number } & \multicolumn{5}{|c|}{ Letters } & \multicolumn{5}{|c|}{ Words } \\
\hline & \multicolumn{2}{|c|}{ Intervention $(n=133)$} & \multicolumn{2}{|c|}{ Control $(n=136)$} & \multirow[t]{2}{*}{$t(267)$} & \multicolumn{2}{|c|}{ Intervention $(\mathrm{n}=174)$} & \multicolumn{2}{|c|}{ Control $(n=171)$} & \multirow[t]{2}{*}{$t(343$} \\
\hline & $M$ & $\mathrm{SD}$ & $M$ & SD & & M & SD & $M$ & $\mathrm{SD}$ & \\
\hline $\begin{array}{l}\text { Total } \\
\text { attempts }\end{array}$ & 37.77 & 19.61 & 31.40 & 20.53 & $2.57^{*}$ & 17.59 & 10.99 & 14.30 & 11.23 & $4.34^{* *}$ \\
\hline Errors & 1.20 & 1.63 & 1.90 & 2.05 & $-3.14^{* *}$ & 1.54 & 1.76 & 2.07 & 1.93 & $-2.10 * *$ \\
\hline
\end{tabular}

${ }^{*} p<.05,{ }^{* *} p<.01$

Figure 4 displays the percentage frequency distribution of post-test word reading scores per minute for the intervention and control groups. The percentage of students at the lower end of the score range was higher in the control group than in the intervention group. In particular, twice as many students scored zero on the post-test in the control group ( $n=27,16 \%$ ) as students in the intervention group ( $n=14,8 \%$ ).

\section{Figure 4}

Percentage Frequency Distribution of Post-test Word Reading Scores Per Minute in the Intervention and Control Groups

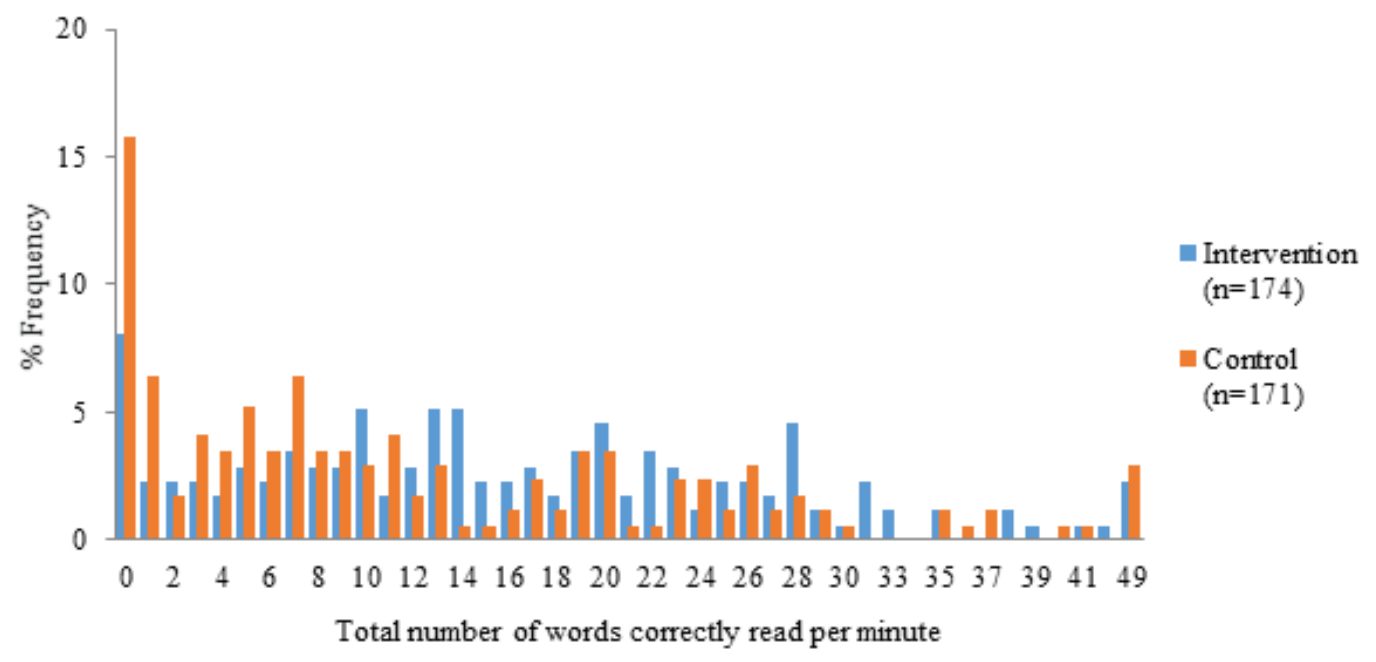




\subsection{Research Question 2: Accuracy differences in letter identifica- tion and word reading}

To examine any differences in students' accuracy in identifying letters in an entire list and reading words in a text of 49 words between the intervention and control groups, the total number of letters identified and words read correctly were compared using a series of t-tests. As shown in Table 4, on the pre-test, no significant mean differences emerged in the letter identification and word reading between the intervention and control groups. When the students were tested at mid-year, however, the group of students using lqra performed significantly higher on average than those in the control group on both letter identification $(t(267)=2.83, p=.005,95 \% \mathrm{Cl}[4.13,23.01], d=0.35)$ and word reading assessments $(t(343)=2.49, p=.013,95 \% \mathrm{Cl}[0.99,8.35], d=0.27)$, indicating students in the lqra intervention group identified letters and read words more accurately than those in the control group.

\section{Table 4}

Mean Differences between the Intervention and Control Groups in the Total Number of Letters Identified and Words Read Correctly for the Entire Testing Time

\begin{tabular}{|c|c|c|c|c|c|c|c|c|c|c|}
\hline \multirow[t]{3}{*}{ Time } & \multicolumn{5}{|c|}{ Letters } & \multicolumn{5}{|c|}{ Words } \\
\hline & \multicolumn{2}{|c|}{ Intervention $(n=133$ ) } & \multicolumn{2}{|c|}{ Control $(n=136)$} & \multirow[t]{2}{*}{$t(267)$} & \multicolumn{2}{|c|}{ Intervention $(n=174)$} & \multicolumn{2}{|c|}{ Control $(n=171)$} & \multirow[t]{2}{*}{$t(343)$} \\
\hline & $M$ & SD & M & SD & & $M$ & SD & $M$ & SD & \\
\hline Pre-test & 16.68 & 26.69 & 17.69 & 29.81 & -0.29 & 1.07 & 5.17 & 1.11 & 3.15 & -0.09 \\
\hline Mid-test & 52.84 & 39.62 & 39.27 & 38.98 & $2.83^{* *}$ & 16.65 & 17.45 & 11.98 & 17.32 & $2.49^{*}$ \\
\hline Post-test & 74.17 & 36.63 & 59.34 & 41.91 & $3.09^{* *}$ & 29.56 & 19.03 & 20.55 & 19.21 & $4.38^{* * *}$ \\
\hline $\begin{array}{l}\text { Difference } \\
\text { (post-test - } \\
\text { pre-test) }\end{array}$ & 57.50 & 41.42 & 41.65 & 43.40 & $3.06^{* *}$ & 28.49 & 19.20 & 19.44 & 18.65 & $4.44^{* * *}$ \\
\hline
\end{tabular}

${ }^{*} p<.05,{ }^{* *} p<.01,{ }^{* * *} p<.001$

To examine if students in the intervention group outperform students in the control group in terms of accuracy of letter identification and word reading after participating in a full-year lqra intervention, the post-test means between two groups were compared. As presented in Table 4, the intervention group scored significantly higher on average on both the total number of correct letters they identified $(t(267)=3.09, p=.002,95 \%$ $\mathrm{Cl}[5.38,24.29], d=0.38)$ and number of correct words they read $(t(343)=4.38, p<$ $.001,95 \% \mathrm{Cl}[4.97,13.06], d=0.47)$ than the control group. Students in the intervention group correctly identified approximately 15 more letters and read nine more words than those in the control group. When comparing the gain scores between pre- and post-test between two groups, significant differences are found with the students using the Iqra curriculum making greater gains on average than other students $(t(267)=3.06, p=.002$, $95 \% \mathrm{Cl}[5.66,26.04], d=0.37$ for letters; $t(343)=4.44, p<.001,95 \% \mathrm{Cl}[5.05,13.06], d=$ 0.48 for words). The students of the intervention group identified approximately 58 more letters and read 28 more words correctly on average on the post-test assessments than the pre-test assessments while those in the control group made gains in approximately 42 letters and 19 words on average from their pre-test assessments. 
Figure 5 and Figure 6 also display the pre-test, mid-test, and post-test means between the intervention and control groups in the total number of letters identified and words read correctly, showing the higher performance of the intervention group in the accuracy of identifying letters and reading words.

\section{Figure 5}

Pre-test, Mid-test, and Post-test Means of the Intervention and Control Groups on Total Letter Identification Assessment

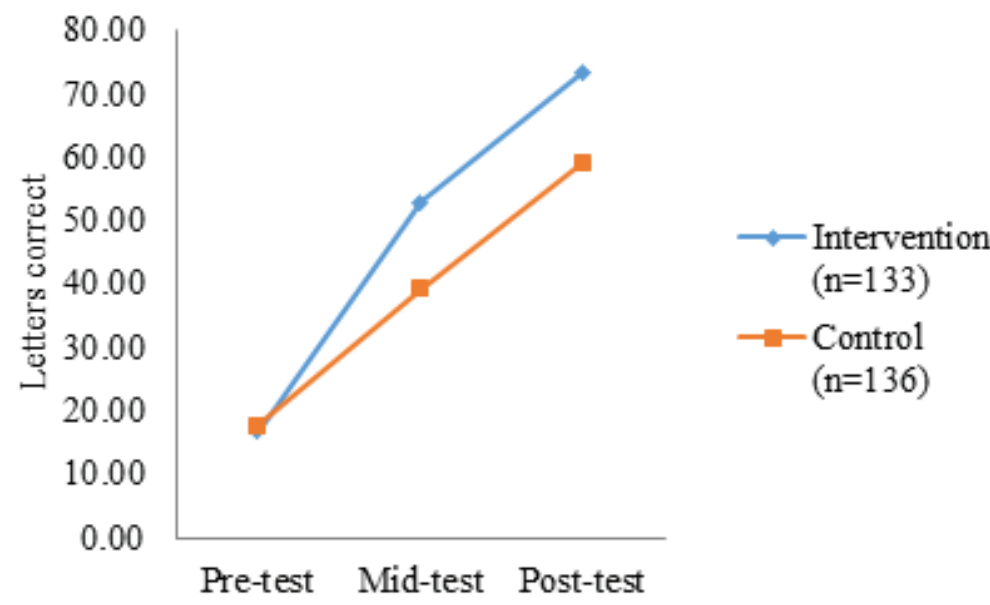

\section{Figure 6}

Pre-test, Mid-test, and Post-test Means of the Intervention and Control Groups on Total Reading Assessment of 49 Words

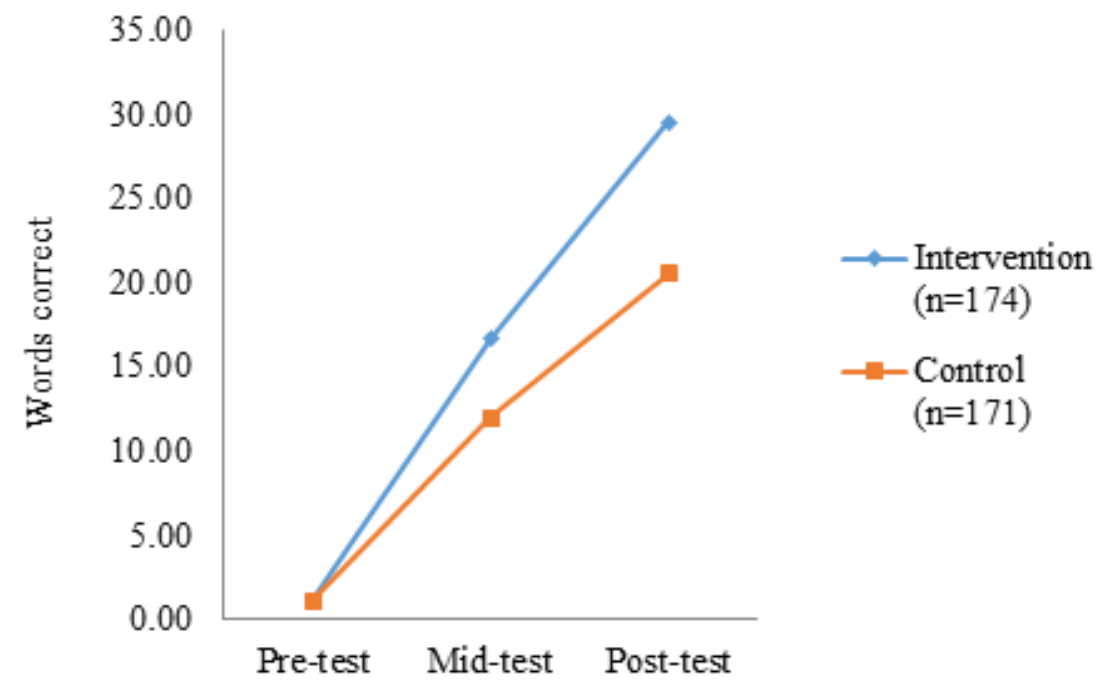

In terms of the average percent correct for letter identification, there was no notable difference between the two groups (97\% for the intervention and $96 \%$ for the control group), indicating both groups reached a high level of accuracy in letter identification. As shown in Table 5, however, the intervention group identified significantly more letters 
$(t(267)=3.08, p=.002,95 \% \mathrm{Cl}[5.11,23.27], d=0.38)$ and made fewer errors $(t(267)=$ $-2.43, p=.002,95 \% \mathrm{Cl}[-1.17,-0.12], d=-0.30$ ) on average than the control group. The percent correct for word reading was also higher for the intervention group than for the control group, indicating the students in the lqra classrooms could read words correctly on average with 92 percent accuracy, whereas those in the control group read words correctly with 86 percent accuracy.

\section{Table 5}

Post-test Mean Numbers of Letters and Words Attempted and Errors Made for the Intervention and Control Groups

\begin{tabular}{|c|c|c|c|c|c|c|c|c|c|c|}
\hline \multirow[t]{3}{*}{ Number } & \multicolumn{5}{|c|}{ Letters } & \multicolumn{5}{|c|}{ Words } \\
\hline & \multicolumn{2}{|c|}{ Intervention $(n=133)$} & \multicolumn{2}{|c|}{ Control $(n=136)$} & \multirow[t]{2}{*}{$t(267)$} & \multicolumn{2}{|c|}{ Intervention $(n=174)$} & \multicolumn{2}{|c|}{ Control $(n=171)$} & \multirow[t]{2}{*}{$t(343)$} \\
\hline & $M$ & SD & $M$ & $\mathrm{SD}$ & & $M$ & $\mathrm{SD}$ & $M$ & $\mathrm{SD}$ & \\
\hline $\begin{array}{l}\text { Total } \\
\text { attempts }\end{array}$ & 76.29 & 35.07 & 62.10 & 40.33 & $3.08^{* *}$ & 32.31 & 18.04 & 23.78 & 18.49 & $4.34^{* * *}$ \\
\hline Errors & 2.12 & 2.10 & 2.76 & 2.24 & $-2.43^{*}$ & 2.75 & 2.19 & 3.23 & 2.12 & $-2.10^{*}$ \\
\hline
\end{tabular}

${ }^{*} p<.05,{ }^{* *} p<.01,{ }^{* * *} p<.001$

Figure 7 displays the percentage frequency distribution of the total number of words students read correctly in a 49-word text. As shown in Figure 7, more students scored zero on the post-test in the control group (16\%) rather than in the intervention group (8\%). Overall, the proportion of students at the lower end of the post-test score distribution was greater in the control group than in the intervention group, while that of students at the higher end was larger in the intervention group than in the control group.

\section{Figure 7}

Percentage Frequency Distribution of Total Number of Post-test Word Reading Scores in the Intervention and Control Groups

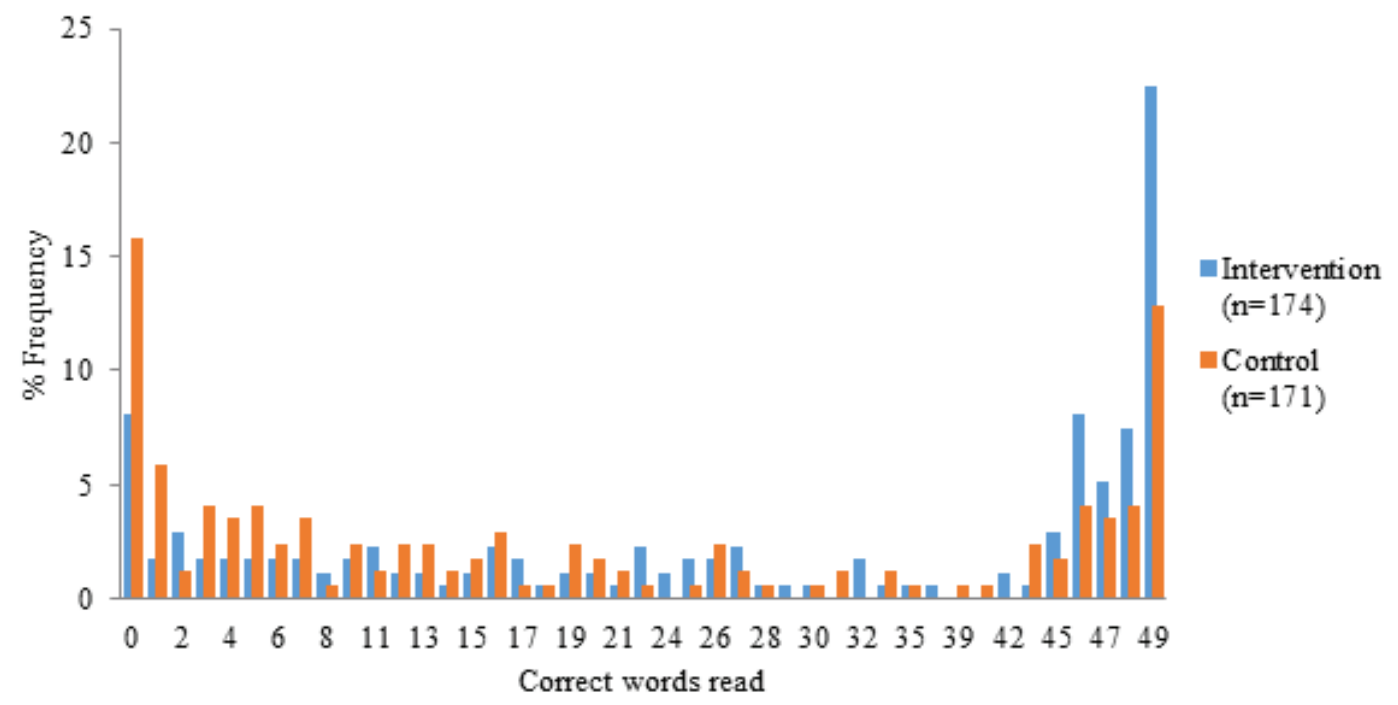




\section{Discussion}

By the end of one year, students who used the lqra curriculum demonstrated better performance on assessments of reading fluency than students who used only the mainstream reading curriculum. Iqra students were able to identify letters and read words with more speed and accuracy than their peers who were not using the lqra curriculum. In addition, lqra students attempted to identify more letters and made fewer errors than their peers. This points to a greater degree of persistence in reading among the students who used the Iqra curriculum.

The results of this pilot suggest that students' reading fluency increased due to the design of the lqra textbook. The textbook included repetition of letter patterns and blending letters to increase both speed and accuracy (Pariyadath et. al, 2012; Speelman \& Kirsner, 2005). The lqra textbook's simple design that minimized visual crowding by leaving space between letters and words and included few images helped students focus on the text on each page (Chung, 2002; Zhu et al., 2016; Levi, 2008). Keeping the harakat in the text also trained the students to recognize words more accurately (Maroun \& Hanley, 2017).

From a reading method perspective, the study results encourage the use of perceptual learning parameters. The results also support findings from work in other languages and scripts to incorporate perceptual learning in early grade reading instructional materials (Karim et al., 2016; lyengar, 2019).

Scale-up of this perceptually enhanced curriculum in other countries would necessitate alignment with local ministries of education and synchronization with textbook developers to incorporate perceptual learning across instructional materials. Support would also be needed to orient language instructors to the cognitive processes involved in reading fluency and comprehension and the features and benefits of the Iqra approach.

\section{Limitations}

Iqra and its evaluation are still in formative stages. It remains to be seen if the results could be replicated in other Arab-speaking contexts and with larger sample sizes. Convenience sampling meant there were some limitations regarding the extent to which demographic information was collected. Previous research in this particular area of the UAE has shown that students are at a similar socioeconomic level (Buckner, 2018). However, without concrete data, the impact of lqra could not be correlated to family circumstances in this study. Variables that could be affecting students' reading fluency, such as exposure to MSA should be explored to better control for the effects of the lqra curriculum on students' reading fluency. In addition, potential confounding variables at individual schools using the lqra curriculum need to be considered and identified during the research process.

Due to the schools' voluntary participation in the lqra pilot, students in intervention classrooms did not participate in lqra only, but rather in addition to their regular Arabic classes. This study design makes it difficult to differentiate between an lqra effect versus 
a simple extra-lesson effect. It cannot be certain how effective regular additional Arabic instruction would be in comparison to Iqra. Also, Iqra instructional time was limited. Although there should have been two 45-minute lqra lessons per week, actual instruction time was not recorded. The period in which lqra was taught was a free period that was sometimes used for special school activities instead of lqra. In addition, individual students' time-on-task during lqra lessons was not measured. The first graders, with their short attention spans would sometimes be distracted. In these cases, instructors would bring the students' attention back to the lesson, but some instructional time was lost.

Finally, reading comprehension was not assessed in this pilot. This was due to the assumption that students would not know enough Standard Arabic to be able to complete comprehension exercises. However, a subsequent study could include a comprehension assessment to see whether a difference would be seen over the course of the reading intervention.

\section{Future research}

\subsection{Perceptual Features}

Greater understanding is needed of how perceptual features of reading instruction materials can be optimized for increased impact. This could partially be addressed by incorporating a general classroom observation tool, such as the Stallings classroom observation system to gauge students' level of engagement with the Iqra materials (World Bank, 2015). While observing students can help to better approximate elements such as text size and spacing needed to facilitate perceptual learning, more sophisticated tools, such as eye tracking devices could be employed for more precise measurements (Abadzi, 2007; Jankovski \& Schofield, 2017).

\subsection{Struggling Students}

Even though Iqra seemed to help students increase their reading fluency, some students did not improve as much as others. Follow up research could explore better ways to help students who were identified through initial lqra assessments as not performing as well. For example, an instructor or assistant could work one-on-one using the lqra textbook with struggling students to see whether there would be an impact.

\subsection{Demographic Information}

Demographic information is a potentially important predictor of student achievement. Thus, future research should collect more demographic information to look for any differences in reading performance that could be correlated with students' family circumstances. This could include the amount of exposure students have to MSA outside of school and students' access to extracurricular support such as private tutoring. 


\section{Conclusion}

This study demonstrated that students who participated in the Iqra curriculum had improved reading fluency after one year in comparison to their peers in the same school. Whether these gains translate into improved education performance over time may be evident when international assessment results are available for participating students.

Policy considerations coming out of this study include how to adopt the lqra curriculum and other data-driven methods to improve early grade Arabic language instruction on a larger scale in the UAE and other Arabic-speaking countries where students are performing below the global average. This study affirmed that the Iqra curriculum is a low-cost intervention. It can be implemented successfully with minimal resources, training, and external support.

Another promising finding from this study is that students with more exposure to Arabic instruction performed significantly higher than peers in their same school. Increasing the amount of Arabic language instruction in the school schedule is a potential first step in helping students improve their reading fluency. While the "Iqra effect" may not be easily isolated within the current pilot implementation structure, future studies could compare students using lqra with other students using an alternative supplement to their traditional Arabic language class.

\section{Author Biographies}

Dr. Elisabeth Wilson is the Director of Programs at the Sheikh Saud bin Saqr Al Qasimi Foundation for Policy Research. She received a doctorate degree in Educational Policy and Administration from the University of Minnesota.

Dr. Soohyun Jeon is the former Research Director and a current Non-Resident Researcher at the Sheikh Saud bin Saqr Al Qasimi Foundation for Policy Research. She received a doctorate degree in Educational Psychology from the University of lowa.

Holly Cook is a Non-Resident Researcher at the Sheikh Saud bin Saqr Al Qasimi Foundation for Policy Research. She has a master's degree in International and Comparative Education from Teachers College, Columbia University.

Dr. Helen Abadzi is a Greek psychologist, polyglot, World Bank retiree, and a researcher at the University of Texas at Arlington where she also received a doctorate in psychology. Email: habadzi@uta.edu.

\section{Acknowledgements}

The authors would like to thank Hanadi Mohammed, Gehad Al Njar, Reham Zahran, and Rafia Aldhahouri for their roles in the implementation of this pilot as well as the school principals, instructors, and students for their indispensable support. 


\section{Notes}

1. While there is disagreement around the extent to which socio-economic status causes variance in student assessment scores across and within countries, students' socioeconomic status does appear to correlate with the PISA results (Asil \& Brown, 2015). In the UAE, students from higher socioeconomic levels scored higher on reading than disadvantaged students by 105 points which was a larger gap than the global average. Only seven percent of disadvantaged students scored in the top 25 percent compared to 11 percent of students globally (OECD, 2019).

2. As the Iqra curriculum was developed, the Foundation tested the materials with grade one students at a government school in Ras Al Khaimah that had participated in teacher professional development activities organized by the Foundation in the past. Although there were only 50 students in the initial pilot of the lqra curriculum which lasted less than three months, there were nascent promising results.

3. Students who were identified as having learning difficulties by their school were not included in the final analysis considering the potential confounding effects of the following factors: (1) students' reading speed and accuracy may differ depending on the types of and degree of the learning difficulties; (2) half of these students did not take post-tests; and (3) classroom observations revealed that the way the lessons were delivered to these students differed across instructors (some provided extra help and support but some did not).

4. In general, across Ras Al Khaimah government schools, socioeconomic differences have not been shown to significantly impact school performance (Buckner, 2018).

5. The primary focus of this study was to examine if students in the lqra intervention group identify letters and read words faster and more accurately than students in the control group after participating in a full-year intervention, rather than to compare the time trends across the three time points between the two groups. Therefore, independent samples t-tests were chosen for the comparisons of the post-test means between the two groups whose pre-test means were not significantly different on both letter identification and word reading assessments.

6. Students from School 1 initially demonstrated a higher average number of letters identified correctly than any other group, but their scores declined from the pre-test to mid-year assessment. This was likely due to a measurement error at the pre-test. Therefore, this school's data was excluded for the final analysis for speed and accuracy of letter identification (intervention $n=133$; control $n=136$ ).

7. The percent correct score was estimated by dividing the total number of errors made by the total number of letters or words attempted and then subtracting the obtained value of each group from one.

\section{References}

[1] Abadzi, H. (2007). Absenteeism and beyond: Instructional time loss and consequences. (Policy Research Working Paper No. 4376). World Bank. https://openknowledge.worldbank.org/handle/10986/ 7569 
[2] Abadzi, H. (2017). Improving Arab students' academic achievement: The crucial role of rapid reading and grammar mastery in the early grades. (Policy Paper No. 20). Sheikh Saud bin Saqr Al Qasimi Foundation for Policy Research. https://doi.org/10.18502/aqf.0047

[3] Abadzi, H., \& Martelli, M. (2014, November). Efficient reading for Arab students: Implications from neurocognitive research [Conference presentation]. World Innovation Summit for Education. Doha, Qatar.

[4] Abdelhadi, S., Ibrahim, R. \& Eviatar, Z. (2011). Perceptual load in the reading of Arabic: Effects of orthographic visual complexity on detection. Writing Systems Research, 3(2), 117-127. http://doi.org/10. 1093/wsr/wsr014.

[5] Abu-Leil, A.K., Share, D.L., Ibrahim, R. (2014). How does speed and accuracy in reading relate to reading comprehension in Arabic? Psicologica, 35(2), 251-276. https://files.eric.ed.gov/fulltext/EJ1046114.pdf

[6] Abu-Rabia, S. (1999). The effect of Arabic vowels on the reading comprehension of second- and sixthgrade native Arab children. Journal of Psycholinguistic Research, 28(1), 93-101. https://pubmed.ncbi. nlm.nih.gov/9949716/

[7] Abu-Rabia, S. (2001). The role of vowels in reading Semitic scripts: Data from Arabic and Hebrew. Reading and Writing, 14, 39- 59. http://doi.org/10.1023/A:1008147606320

[8] Al-Hendawi, M. \& Keller, C. (2014). Beyond the walls of the school: Risk factors and children and youth in the Gulf. Near and Middle Eastern Journal of Research in Education, 2014(1), 1-7. http://dx.doi.org/10. 5339/nmejre.2014.1

[9] Asadi, I. A., Khateb, A., \& Shany, M. (2017). How simple is reading in Arabic? A cross-sectional investigation of reading comprehension from first to sixth grade. Journal of Research in Reading, 40, S1-S22. https://onlinelibrary.wiley.com/doi/full/10.1111/1467-9817.12093

[10] Asil, M. and Brown, G. (2015). Comparing OECD PISA Reading in English to Other Languages: Identifying Potential Sources of Non- Invariance. International Journal of Testing, 16(1), 71-93. http://doi.org/10.1080/ 15305058.2015.1064431

[11] Ayari, S. (1996). Diglossia and illiteracy in the Arab world. Language, Culture and Curriculum, 9(3), 243-252. https://doi.org/10.1080/07908319609525233

[12] Buckner, E. (2018). The Other Gap: Examining Low-Income Emiratis' Educational Achievement. (Working Paper 15). Sheikh Saud bin Saqr Al Qasimi Foundation for Policy Research.

[13] Carnine, D., Silbert, J. \& Kameenui, E. J. (1990). Direct instruction reading (2nd ed.). Prentice Hall

[14] Carroll, K., Al Kahwaji, B., \& Litz, D. (2017). Triglossia and promoting Arabic literacy in the United

[15] Arab Emirates. Language, Culture, \& Curriculum, 30(3), 317-332. https://doi.org/10.1080/07908318.2017. 1326496

[16] Chudgar, A., \& Luschei, T. F. (2009). National income, income inequality, and the importance of schools: A hierarchical cross-national comparison. American Educational Research Journal, 46(3), 626-658. https://doi.org/10.3102/0002831209340043

[17] Chung, S.T. L. (2002). The effect of letter spacing on reading speed in central and peripheral vision. Investigative Ophthalmology \& Visual Science, 43(4), 1270-1276. https://pubmed.ncbi.nlm.nih.gov/ $11923275 /$

[18] Dehaene, S., Cohen, L., Morais, J. \& Kolinsky, R. (2015). Illiterate to literate: Behavioural and cerebral changes induced by reading acquisition. Nature Reviews Neuroscience, 16(4), 234-244. http://dx.doi. org.tc.idm.oclc.org/10.1038/nrn3924

[19] Eviatar, Z., \& Ibrahim, R. (2014). Why is it hard to read Arabic? In Saiegh-Haddad, E., \& Joshi, R. M. (Eds.), Handbook of Arabic literacy (pp. 77-96). Springer. http://doi.org/10.1007/978-94-017-8545-7

[20] Fryer, R. G., \& Levitt, S. D. (2010). An empirical analysis of the gender gap in mathematics. American Economic Journal: Applied Economics, 2(2), 210-240. http://doi.org/10.1257/app.2.2.210

[21] Fuchs, L. S., Fuchs, D., Hosp, M. K., \& Jenkins, J. R. (2001). Oral reading fluency as an indicator of reading competence: A theoretical, empirical, and historical analysis. Scientific Studies of Reading, 5(3), 239-256. https://doi-org.tc.idm.oclc.org/10.1207/S1532799XSSR0503_3

[22] Gibson, E.J. (1963). Perceptual learning. Annual Review of Psychology, 14(1), 29-56. http://doi.org/10. 1146/annurev.ps.14.020163.000333

[23] Gori, S., \& Facoetti, A. (2014). Perceptual learning as a possible new approach for remediation and prevention of developmental dyslexia. Vision Research, 99, 78-87. https://doi.org/10.1016/j.visres.2013. 11.011

[24] Goulandris, N. (Ed.). (2003). Dyslexia in different languages: Cross-linguistic comparisons. Whurr Publishers.

[25] Green, C. S., Kattner, F., Siegel, M. H., Kersten, D., \& Schrater, P.R. (2015). Differences in perceptual learning transfer as a function of training task. Journal of Vision, 15(10), 1-14. http://doi.org/10.1167/15.10.5

[26] Ibrahim, R., \& Aharon-Peretz, J. (2005). Is literary Arabic a second language for native Arab speakers? Evidence from semantic priming study. Journal of Psycholinguistic Research, 34(1), 51-70. http://doi.org/ 10.1007/s10936-005-3631-8 
[27] lyengar, R. (2019). Using cognitive neuroscience principles to design efficient reading programs: Case studies from India and Malawi cognitive neuroscience to design literacy programs. International Journal of Contemporary Education, 2(2), 38-51. https://doi.org/10.11114/ijce.v2i2.4394

[28] Iyengar, R. (2018, August 21). Reading Program Improves Child Literacy Rates in Indian District. State of the Planet. https://blogs.ei.columbia.edu/2018/08/21/reading-program-child-literacy-india/

[29] Jackson, A. \& Kiersz, A., (2016, December 6). The latest ranking of top countries in math, reading, and science is out - and the US didn't crack the top 10. Business Insider. http://www.businessinsider.com/ pisa-worldwide-ranking-of-math-science-reading-skills-2016-12

[30] Jankovski, C., \& Schofield, D. (2017). The eyes have it: Using eye tracking technology to assess the usability of learning management systems in elementary schools. European Journal of Education Studies, 10(3), 425-458. https://doi.org/10.5281/zenodo.1034181

[31] Karim, A., Changwira, F., \& lyengar, R. (2016). Contextualization of a cognitive-science based learning package for low-resourced settings in Malawi. Journal of Education and Training Studies, 4(5), 183-195.

[32] Kirby, J. R., Parrila, R. K., \& Pfeiffer, S. L. (2003). Naming speed and phonological awareness as predictors of reading development. Journal of Educational Psychology, 95(3), 453-464. http://doi.org/10.1037/ 0022-0663.95.3.452

[33] Klauda, S. L., \& Guthrie, J. T. (2008). Relationships of three components of reading fluency to reading comprehension. Journal of Educational Psychology, 100(2), 310-321. http://dx.doi.org.tc.idm.oclc.org/ 10.1037/0022-0663.100.2.310

[34] Knipp, K. (2014). Arabic: the last tie that binds. Qantara.de. https://en.qantara.de/content/ the-arab-world-arabic-the-last-tie-that-binds

[35] LaBerge, D., \& Samuels, S. J. (1974). Toward a theory of automatic information processing in reading. Cognitive Psychology, 6(2), 293-323. https://doi.org/10.1016/0010-0285(74)90015-2

[36] Levi D. M. (2008). Crowding-An essential bottleneck for object recognition: A mini-review. Vision Research, 48(5), 635-654. https://doi.org/10.1016/j.visres.2007.12.009

[37] Mahfoudhi, A., Everatt, J., \& Elbeheri, G. (2011). Introduction to the special issue on literacy in Arabic. Reading and Writing, 24(9), 1011-1018. https://doi.org/10.1007/s11145-011-9306-y

[38] Maroun, M. \& Hanley, J. (2017). Diacritics improve comprehension of the Arabic script by providing access to the meanings of heterophonic homographs. Reading and Writing, 30, 319-335. https://doi. org/10.1007/s11145-016-9677-1

[39] Miller, G. (1956). The magical number seven, plus or minus two: Some limits on our capacity for processing information. The Psychological Review, 63(2), 81-89. https://pure.mpg.de/rest/items/item_ 2364276_4/component/file_2364275/content

[40] Natour, Y. S., Darawsheh, W., Sartawi, A. M., Marie, B. A., \& Efthymiou, E. (2016). Reading error patterns prevailing in Arab Emirati first graders. Cogent Education, 3(1), 1-17. https://doi.org/10.1080/2331186X 2016.1226459

[41] OECD. (2019). Country Note: Programme for International Student Assessment Results from PISA 2018. United Arab Emirates. https://www.oecd.org/pisa/publications/PISA2018_CN_ARE.pdf

[42] OECD. (2015). The ABC of gender equality in education. PISA. OECD Publishing. https://www.oecd. org/pisa/keyfindings/pisa-2012-results-gender-eng.pd

[43] Pariyadath, V., Plitt, M., Churchill, S.J., Eagleman, D.M. (2012). Why Overlearned Sequences are Special: Distinct Neural Networks for Ordinal Sequences. Frontiers in Human Neuroscience, http://doi.org/10. 3389/fnhum.2012.00328.

[44] Pelli, D. G., Tillman, K. A., Freeman, J., Su, M., Berger, T.D., \& Majaj, N. J. (2007). Crowding and eccentricity determine reading rate. Journal of Vision, 7(20), 1-36

[45] Perfetti, C.A. (2007). Reading ability: Lexical quality to comprehension. Scientific Studies of Reading 11(4), 357- 383. http://doi.org/10.1080/10888430701530730.

[46] Perfetti, C.A. (1992). The representation problem in reading acquisition. In P.B. Gough, L.C. Ehri \& R. Treiman (Eds.), Reading acquisition (pp. 145-174). Erlbaum.

[47] Peterson, L. R., \& M. J. Peterson. (1959). Short-term retention of individual verbal items. Journal of Experimental Psychology, 58(3), 193-198. https://psycnet-apa-org.tc.idm.oclc.org/fulltext/ 1960-05499-001.pdf

[48] Rashid, N.A. (2011). Neural network based segmentation algorithm for Arabic characters recognition. Journal of Babylon University: Journal of Applied and Pure Sciences, 19(3), 823-828. https://search. emarefa.net/detail/BIM-287934

[49] Ridge, N., Kippels, S., \& Chung, B. (2017). The Challenges and Implications of a Global Decline in the Educational Attainment and Retention of Boys. https://learningportal.iiep.unesco.org/en/library/the-c hallenges-and-implications-of-a-global-decline-in-the-educational-attainment-andRTIInternational.

[50] RTI International. (2016). Early Grade Reading Assessment (EGRA) toolkit. https://learningportal.iiep. unesco.org/en/notice/t1486816404 
[51] Saiegh-Haddad, E. (2007). Linguistic constraints on children's ability to isolate phonemes in Arabic. Applied Psycholinguistics, 28(4), 607-625. https://doi.org/10.1017/S0142716407070336

[52] Saiegh-Haddad, E. (2003). Linguistic distance and initial reading acquisition: The case of Arabic diglossia. Applied Psycholinguistics, 24(3), 431-451. https://doi.org/10.1017/S0142716403000225

[53] Saiegh-Haddad, E. \& Joshi, M. (2014). Handbook of Arabic literacy: Insights and perspectives. Literacy Studies, 9. Springer.

[54] Schiff, R., \& Saiegh-Haddad, E. (2018). Development and relationships between phonological awareness, morphological awareness and word reading in spoken and standard Arabic. Frontiers in Psychology, 9, https://link-gale-com.tc.idm.oclc.org/apps/doc/A533955062/AONE?u=new30429\&sid= AONE\&xid=1f20971a

[55] Seymour, P. H. K., Aro, M., \& Erskine, J. M. (2003). Foundation literacy acquisition in European orthographies. British Journal of Psychology, 94(2), 143-174. https://link-gale-com.tc.idm.oclc.org/apps/ doc/A102947727/AONE?u=new30429\&sid=AONE\&xid=5c75edb3

[56] Speelman, C. \& Kirsner, K. (2005). Beyond the learning curve: The construction of mind. Oxford University Press. http://doi.org/10.1093/acprof:oso/9780198570417.001.0001

[57] Taha, H. Y. (2013). Reading and spelling in Arabic: Linguistic and orthographic complexity. Theory and Practice in Language Studies, 3(5), 721-727. https://doi.org/10.4304/tpls.3.5.721-727

[58] Taha, H. \& Saiegh-Haddad, E. (2016). The role of phonological versus morphological skills in the development of Arabic spelling: An intervention study. Journal of Psycholinguist Research, 45(3), 507 535. http://doi.org/10.1007/s10936-015-9362-6

[59] Tibi, S. \& Kirby, J.R. (2017). Investigating phonological awareness and naming speed as predictors of reading in Arabic. Scientific Studies of Reading. 22(1), 70-84. http://doi.org/10.1080/10888438.2017. 1340948

[60] United Arab Emirates Ministry of Education. (2017). Strategic Plan 2017-2021. https://www.moe.gov.ae/ En/AboutTheMinistry/Pages/MinistryStrategy.aspx

[61] Watanabe, T. \& Sasaki, Y. (2015). Perceptual learning: Towards a comprehensive theory. Annual Review of Psychology, 66, 197-221. http://doi.org/10.1146/annurev-psych-010814-015214.

[62] World Bank. (2015). Conducting classroom observations: Analyzing classroom dynamics and instructional time using the Stallings "classroom snapshot" observation system. User Guide. http://documents.worldbank.org/curated/en/790221467997639302/pdf/ 97904-WP-Box391498B-PUBLIC-WB-Stallings-web.pdf

[63] Yigal, A., \& Sekuler, R. (2008). Geometric structure and chunking in reproduction of motion sequences. Journal of Vision, 8(1), 1-12. https://doi.org/10.1167/8.1.11

[64] Zhu, Z., Fan, Z., \& Fang, F. (2016). Two-stage perceptual learning to break visual crowding. Journal of Vision, 16(6). https://doi.org/10.1167/16.6.16

[65] Ziegler, J. C., \& Goswami, U. (2005). Reading Acquisition, Developmental Dyslexia, and Skilled Reading across Languages: A Psycholinguistic Grain Size Theory. Psychological Bulletin, 131(1), 3-29. http://dx. doi.org/10.1037/0033-2909.131.1.3 